\title{
Variation of Pore Water Pressure in Tailing Sand under Dynamic Loading
}

\author{
Jia-xu Jin, ${ }^{1}$ Hong-zhi Cui $\mathbb{D}^{1},{ }^{1}$ Li Liang, ${ }^{2}$ Shi-wang Li, ${ }^{1}$ and Ping-yi Zhang ${ }^{1}$ \\ ${ }^{1}$ College of Civil Engineering, Liaoning Technical University, Fuxin, Liaoning Province 123000, China \\ ${ }^{2}$ School of Resource \& Civil Engineering, Northeastern University, Shenyang, Liaoning Province 110819, China \\ Correspondence should be addressed to Hong-zhi Cui; hzcui2016337@163.com
}

Received 19 October 2017; Accepted 1 January 2018; Published 30 January 2018

Academic Editor: Chao Tao

Copyright (c) 2018 Jia-xu Jin et al. This is an open access article distributed under the Creative Commons Attribution License, which permits unrestricted use, distribution, and reproduction in any medium, provided the original work is properly cited.

\begin{abstract}
Intense vibration affects the pore water pressure in a tailing dam, with the tendency to induce dam liquefaction. In this study, experiments were performed wherein model tailing dams were completely liquefied by sustained horizontal dynamic loading to determine the effects of the vibration frequency, vibration amplitude, and tailing density on the pore water pressure. The results revealed four stages in the increase of the tailing pore water pressure under dynamic loading, namely, a slow increase, a rapid increase, inducement of structural failure, and inducement of complete liquefaction. A lower frequency and smaller amplitude of the vibration were found to increase the time required to achieve a given pore water pressure in dense tailings. Under the effect of these three factors - vibration frequency and amplitude and tailing density-the tailing liquefaction time varied nonlinearly with the height from the base of the tailing dam, with an initial decrease followed by an increase. The pore pressure that induced structural failure also gradually decreased with increasing height. The increase in the tailing pore pressure could be described by an S-shaped model. A complementary multivariate nonlinear equation was also derived for predicting the tailing pore water pressure under dynamic loading.
\end{abstract}

\section{Introduction}

An increase in the pore pressure of a tailing dam under dynamic loading is accompanied by a decrease in the shear strength. This causes very large local displacements, which in turn lead to instability of the upstream side of the dam, with the possibility of the instability becoming pronounced. The variation of the pore water pressure under dynamic loading fundamentally impacts the soil strength and is key to analyzing the dynamic stability based on the principle of effective stress. A saturated soil tends to lose its original strength under dynamic loading, transforming into a liquidlike state with severe consequences. The transformation process, which is induced by vibration, is referred to as liquefaction and significantly affects the dynamic strength of the soil. It is characterized by a rapid and sudden loss of strength and thus differs from general cases of loss of dynamic strength [1]. Indeed, the variation of the pore water pressure under vibration, and the consequent liquefaction of the soil, has attracted significant interest among researchers.
Extensive research has been conducted in China and abroad on this subject, with substantial progress recorded [28]. Seed et al. [9] proposed an equation of the pore water pressure in sand to enable prediction of the accumulation and dissipation of the pressure during and after an earthquake. Based on considerable laboratory investigations, Martin et al. [10] proposed more practical empirical models. For investigation of the variation of the pore water pressure in saturated clay during and after an earthquake, Nhan et al. [11] established a model of the accumulation of the multidirectional cyclic shear-induced pore water pressure based on the results of undrained, unidirectional, and multidirectional cyclic shear tests. With regard to the pore water pressure change in interbedded clay and silt, which have special structural properties, Chen and Liu [12] and Zhuang et al. [13] proposed hyperbolic and arcsine models for various consolidation conditions. The models were based on the results of earthquake simulations using cyclic dynamic loads. Regarding isotropic and anisotropic consolidation, Huang et al. [14] and Cai et al. [15] conducted GDS dynamic triaxial 


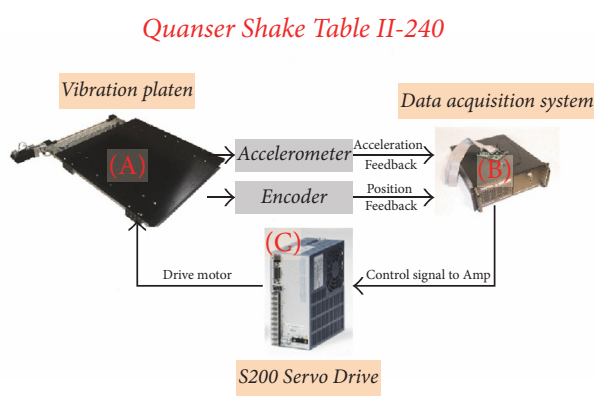

(a)
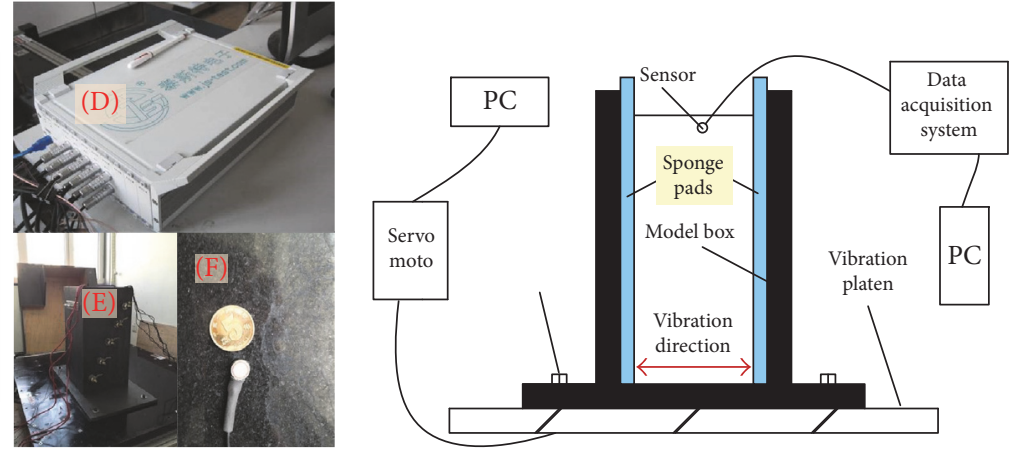

(b)

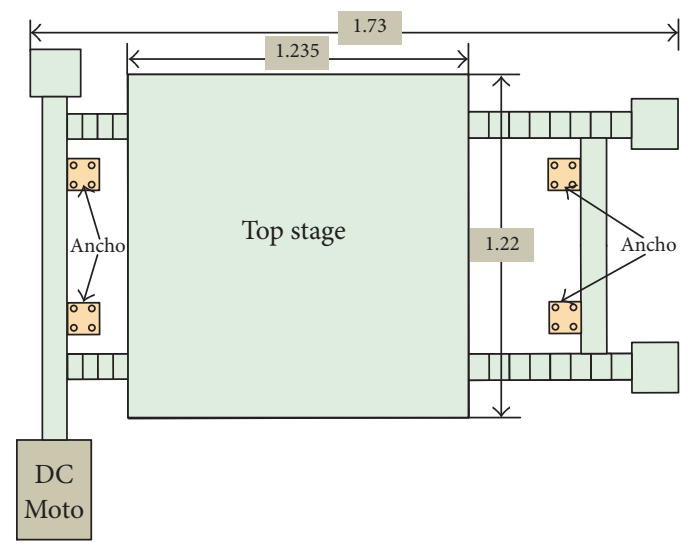

(c)

Figure 1: (a) Experimental equipment and (b) schematic of the experimental system. (c) The diagrammatic drawing of Shake Table II-24 (unit: $\mathrm{m}$ ).

tests (GDS is the short name of A division of Global Digital Systems Ltd) to examine the pore water pressure properties of saturated sand and aeolian sand under cyclic loading and proposed a negative exponential model and logarithmic model.

The models developed in the above-mentioned studies were mainly based on the pore pressure changes in saturated sands under dynamic loading, with only a few considering dynamic pore pressure changes in tailings. Chen et al. [16], Zhang et al. [17], Tan et al. [18], and Du et al. [19] used GDS triaxial tests to investigate the dynamic pore pressure properties of saturated tailings under dynamic loads and put forward models of the pore pressure variation. With regard to common pore pressure stress, strain, and end chronic models, Liu et al. [20] used a stress-controlled undrained dynamic triaxial cyclic shear test and the energy method to investigate the relationship between the pore water pressure and the accumulative energy dissipation in saturated tailing with respect to factors such as the cyclic stress ratio and axialradial consolidation stress ratio. They proposed an energy model of the pore water pressure of the saturated tailing with respect to the stress ratio and axial-radial consolidation stress ratio.

In most of the above-mentioned studies, triaxial tests were used to establish the developed models. However, the majority of them only considered a single factor such as the vibration frequency, with little information provided about the liquefaction of the tailing sand with increasing pore water pressure under dynamic loading, as might be acquired by shaking table tests. In the present study, tailing was used as the raw material and shaking table tests were conducted to investigate the variation of the pore water pressure at different points of a tailing dam with the frequency and amplitude of the vibration and the tailing density. A model of the pore water pressure was developed and used to perform a regression analysis. The findings of this study promise to enable the prediction of the pore water pressure in saturated tailings under dynamic loading and afford a theoretical basis for the design and safe operation of tailing dams.

\section{Experimental Apparatus and Methods}

2.1. Experimental Apparatus. To investigate the variation of the tailing pore pressure under dynamic loading, sine-wave loading was employed in the simulation tests performed on a shaking table. The tailing was thus subjected to shearing by the horizontal acceleration, which effectively mimicked a dynamic load. The tests also enabled the determination of the distribution of the tailing pore water pressure under dynamic loading.

As shown in Figure 1, the experimental system mainly consisted of a Shake Table II-240 $(L \times B=1.220 \mathrm{~m} \times 1.235 \mathrm{~m}$, 
TABLE 1: Physical properties of the tailing sand.

\begin{tabular}{lccccccc}
\hline Plasticity & Liquid limit & Plasticity index & Optimum moisture content & Void ratio & \multicolumn{2}{c}{ Specific gravity } & Maximum dry density \\
$\omega_{p} / \%$ & $\omega_{l} / \%$ & $I_{p} / \%$ & $\omega_{\text {op }}$ & $e$ & $\rho_{d \max }$ & 1.92 \\
\hline $13.1 \%$ & 20.5 & 7.4 & 14.2 & 0.892 & 2.84 & \\
\hline
\end{tabular}

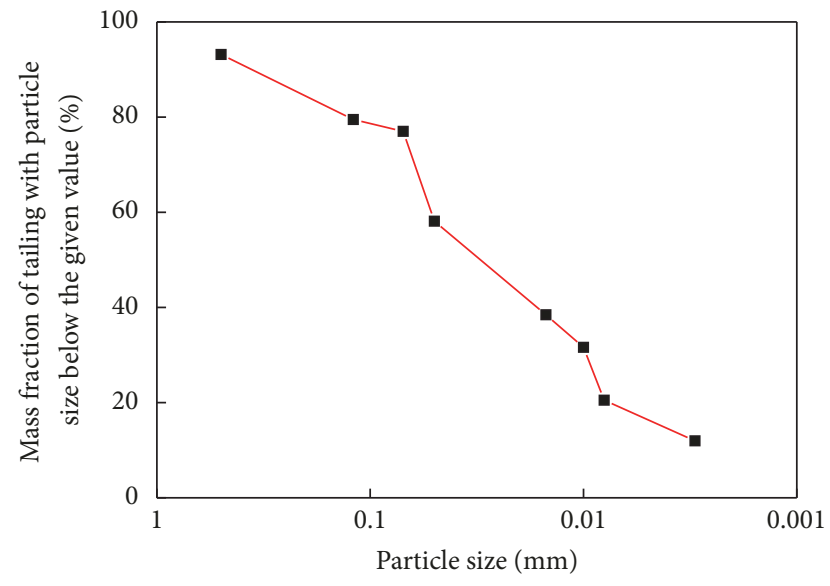

FIgURE 2: Particle size distribution curve.

Figure 1(c)), a data acquisition system, brushless servo drivers, a TST5912 dynamic data acquisition system, a test model box, and a pore water pressure sensor. The maximum acceleration of the shaking table for a $100 \mathrm{~kg}$ load was $1.0 \mathrm{~g}$. The response frequency was within $0-50 \mathrm{~Hz}$ (uniaxial), and the maximum displacement was $119.7 \mathrm{~mm}$. The dynamic data acquisition system has 64 channels, each with a maximum sampling frequency of $100 \mathrm{kHz}$. The distortion and system accuracy are, respectively, less than $0.5 \%$ and $0.5 \%$ F.S. The pore pressure sensor has a measurement range of $0-0.1 \mathrm{MPa}$, operation temperature range of $0-45^{\circ} \mathrm{C}$, and error of $\pm 1 \% \mathrm{~F} \cdot \mathrm{S}$.

2.2. Model Preparation and Experimental Methods. Considering the shaking table test hope that the deformation pattern of the model has a similar vibration process with that of the actual deformation, the influence of the model box on the soil vibration while restraining the soil is controlled within the allowable range. Therefore, the shaking table test is carried out by the methods described as follows.

2.2.1. Model Preparation. The test tailing was obtained from a copper mine in Fuxin, in the Liaoning Province of China. The results of the particle analysis of the tailing are shown in Figure 2, and the basic physical properties are presented in Table 1.

Since the vibration of the free-field prototype foundation is primarily shear vibration, the deformation is mainly shear deformation, and the vibration characteristics of the foundation soil in the experimental stress model box are like the prototype foundation. This requires the shear stiffness of the model box along the vibration direction as small as possible. And box wall material stiffness and thickness are required to satisfy requirements, to prevent or control soil bending deformation. Thus, the internal dimensions of the model box (rigid box) were $300 \times 300 \times 600 \mathrm{~mm}(L \times B \times H)$. As showed in Figure $3, \phi 10 \mathrm{~mm}$ valves spaced at $10 \mathrm{~cm}$ were installed from the bottom to the top of the box to control the water level.

2.2.2. Boundary Processing. The box wall has a restraining effect on the movement of the model foundation to limit the free vibration of the soil around the box wall toward movement. Because the seismic wave cannot be transmitted outwardly on the boundary of the soil, reflected and scattered waves will be generated in the wall of the box. Seismic response of the system of action will have a significant impact. For this reason, the designed model box should minimize the influence of the boundary effect on the research object. Due to the limitation of test conditions, it can be tested in the model box. However, the boundary of the model box has a huge impact on the reflection of the seismic wave energy. Numerous scholars [21, 22] have designed a variety of model box overcoming this kind of problem. At present, there are three main types of model boxes used in shaker tests: rigid model boxes, flexible model boxes, and layered shear models, which can be found in the paper by Mizuno and Iiba (1982) [23], Zhuang et al. (2016) [24], Meymand (1998) [25], Chen et al. [26], Biondi et al. (2015) [6], and Li et al. (2017) [27]. Flexible box and shear box can well reduce the reflection of seismic energy, but they have shortcomings, which make their application restricted. Flexible box to bear the load capacity is limited, and the production of shear box is complex and expensive. Steel box production is simple, the cost is relatively low, but the seismic is large, and the accuracy of test results is affected (Chen et al. (2010) [28]). However, Liu et al. (2015) [29] and Zhuang et al. (2016) [24] suggest that the bubble boundary should be added during the test of pilesoil dynamic interaction; thus the sponge pads were selected for reducing the boundary effect in the paper. Specific content is as follows (Zhuang et al. [24], Liu et al. [29]):

(1) First, in order to reduce the relative slip and ensure a good bond between the tailing sands and bottom of the model box, the bottom plate is made into a friction boundary; that is, the model box is welded with angle steel.

(2) Second, in order to reduce the friction between tailing sand and the side wall of the model and increase the rigidity of tailing sands parallel to the vibration direction, the PVC film is pasted and then lubricating oil is used on its surface.

(3) Finally, in order to minimize the influence of the rigid boundary in the vibration direction, the two side walls of the model box are lined with sponge pads.

2.2.3. Experimental Methods. The test models were fabricated by the dry-pack method to ensure their complete saturation 


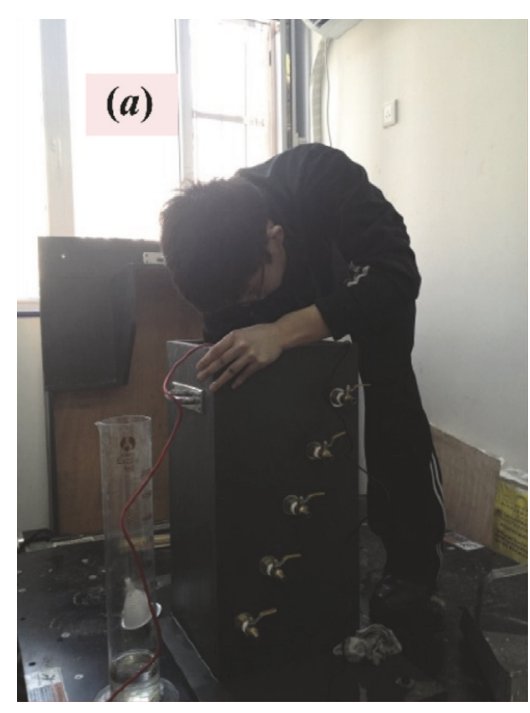

(a)

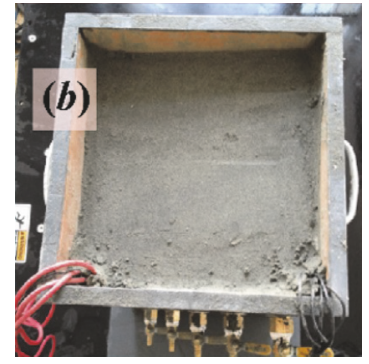

(b)

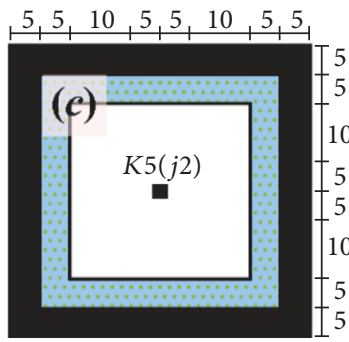

(c)

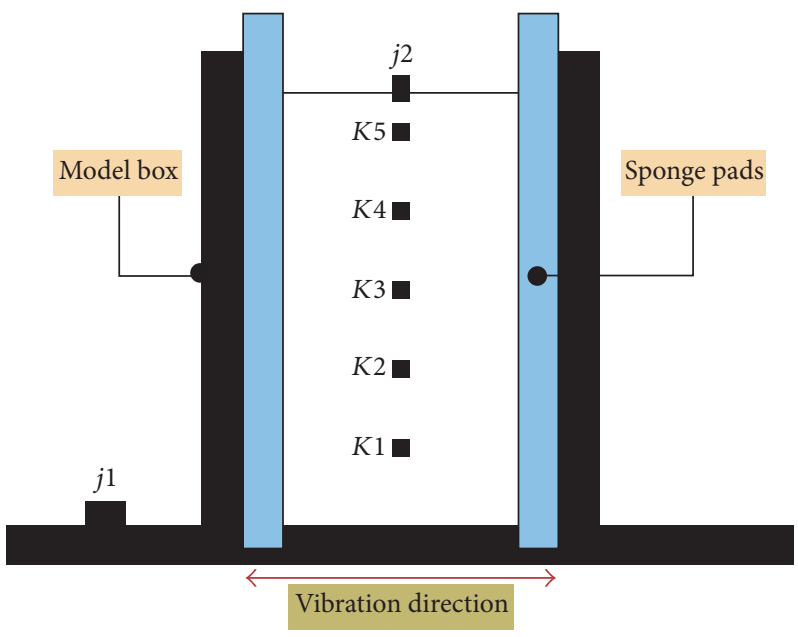

(d)

Figure 3: Model fabrication and pore water sensor placement scheme.

and internal homogeneity, while taking into consideration the effects of the boundary drainage conditions. The specific model preparation steps are as follows: (1) a specified amount of the dry tailing sand was measured, mixed with water to achieve $10 \%$ moisture content, and stirred to homogeneity. (2) The sample was then placed in the model box and slowly compacted to a thickness of $5 \mathrm{~cm}$, especially at the corners. (3) The surface of the sample was treated to ensure good contact with the next sample layer. (4) The next sample layer was applied by repeating the above procedure. For every $10 \mathrm{~cm}$ increase in thickness of the model, pore water pressure sensors numbered $K 1-K 5$ were embedded along the central cross-sectional axis, as shown in Figures 3(c) (unit: $\mathrm{cm}$ ) and 3(d). The pressure-bearing faces of the sensors were turned in the direction to be measured and perpendicular to it. Stability was ensured in the installation so that the pressure-bearing faces of the sensors would not move out of position during the measurement. When the tailing sand layers reached the designated height, the surface was slightly flattened. The water required to maintain $100 \%$ saturation of the model was weighed out and slowly poured into the box several times. The model was then left to stand undisturbed for $48 \mathrm{~h}$, with a $5 \mathrm{~cm}$ thick layer of clay placed on top of it to limit the dissipation rate of the pore water pressure and maintain a more consistent pressure condition. The packed sand box is shown in Figure 3(b).

Acceleration sensors $j 1$ and $j 2$ were installed on the vibration platen and at the top of the model box, respectively. The input acceleration delivered by the control system and the output acceleration of the shaking table were adjusted to be the same, with the values recorded by the sensors considered as the actual acceleration.

Professor Arias [30] of the Universidad de Chile conceived the "mechanical earthquake intensity" in the 1970s and he proposed using the energy $\left(I_{a}\right)$ of a unit particle consumed by single-point elastic system in an earthquake as the total seismic intensity-Arias intensity. In order to propose a new method for reliability analysis of dynamic slope stability with 
TABLE 2: Parameters of the shaking table tests.

\begin{tabular}{lccc}
\hline Test number & $\begin{array}{c}\text { Frequency } \\
f / \mathrm{Hz}\end{array}$ & $\begin{array}{c}\text { Amplitude } \\
A / \mathrm{mm}\end{array}$ & $\begin{array}{c}\text { Density } \\
\rho / \mathrm{kg} \cdot \mathrm{m}^{-3}\end{array}$ \\
\hline$(1)$ & 2.0 & 5 & 1296.30 \\
$(2)$ & 2.4 & 5 & 1296.30 \\
$(3)$ & 2.8 & 5 & 1296.30 \\
$(4)$ & 2.0 & 3 & 1296.30 \\
$(5)$ & 2.0 & 4 & 1296.30 \\
$(6)$ & 2.0 & 5 & 1111.11 \\
$(7)$ & 2.0 & 5 & 1666.67 \\
\hline
\end{tabular}

considering energy-time distribution, Liu et al. (2015) [31] consider that Arias intensity combines more amplitude and duration and carries more vibration information than peak acceleration and peak velocity, so it was used to investigate the significant duration of seismic vibrations which is an indicator of seismic intensity. A well-known cumulative intensity characteristic (Arias intensity) and the equivalent loading cycles were are selected to represent the accumulated energy buildup during a shaking event as observed in papers by Chen et al. (2015) [32], Mirshekari and Ghayoomi (2017) [33], and Tombari et al. (2017) [34].

Meanwhile, many factors can affect the strength of saturated soil liquefaction, including the characteristics of the soil itself (type, density, structure, grading, water permeability, etc.), the initial stress state and dynamic load characteristics (vibration amplitude, vibration frequency, and so on) (Xie [1], Guo and He (2009) [35], and Sun et al. (2015) [36]), and geological age, earthquake history, saturation degree, and field conditions of soil formation (Du et al. (2015) [19]). But vibration frequency is a significant factor affecting the dynamic characteristics of saturated sand.

Although Peacock and Seed (1975) [37], Zhang and Wang (1990) [38], and Wang and Hai (2003) [39] consider that the vibration frequency has little effect on the soil liquefaction when less than $10 \mathrm{~Hz}$, due to the complexity of soil itself, the influence of vibration frequency on soil liquefaction has not yet formed a unified viewpoint. According to the research of frequency by Sun et al. (2015) [36], Feng and Zhang (2013) [40], and Guo and He (2009) [35], taking into account the seismic frequency spectrum analysis of the excellent frequency mostly within $0 \sim 10 \mathrm{~Hz}$ (Sun et al. (2015) [36]) and the frequency range of general earthquake action is $1 \sim 4 \mathrm{~Hz}$ which can be found in the paper by Zhang et al. (2006) [41] and Yoshimi and Oh-Oka (1975) [42], because of limit of the shaking table's own output frequency at the same time, the changes of the pressure change of the tailing sands are studied with the frequency of $2.0 \sim 2.8 \mathrm{~Hz}$.

Consequently, to understand the cumulative pore water pressure, a sinusoidal load is applied to the test model on shaking table using time as an independent variable. Seven scenarios were considered to simulate the effects of three factors (the initial density, vibration amplitude (horizontal), and vibration frequency) on the pore pressure divided into three levels. Specific test conditions are enumerated in Table 2.
2.3. Dynamic Characteristics of Physical Model. The physical model system is composed of tailing sand and a model box, and each of the vibration characteristics has influence on the overall performance. Taking into account the experimental study of the tailing sand under the action of vibration, the tailing sand is the main research object in the model box. In order to reduce the dynamic response of the tailing sand itself, the natural frequency of the rigid box must be far away from the fundamental frequency of the tailings sand. In the same way, in order to avoid damping of the tailing sand, the damping of the model box should be lower than that of tailing sand.

The sweep frequency method is used to measure the natural frequency of the model box. After it is installed on the shaking table, the sine wave is applied to it from low to high, continuous, and uniform changes, and the model box is forced to shake. When the applied sine-wave frequency and the natural frequency of the model box are equal, the test will produce resonance phenomenon of the model box, and the amplitude has a maximum value. The fundamental frequency is $31.79 \mathrm{~Hz}$ of the model box. By inputting the pulse signal on the shaking table, the model box is displaced relative to the ground floor along the vibration direction. With the data monitored by the acceleration sensor, the damping ratio of the model box is $2.15 \%$.

Before the test, in order to determine the natural frequency and damping ratio of tailing sand, 6 times the white noise with an amplitude of $0.1 \mathrm{~g}$ was used to sweep the tailings sand. The natural frequency of tailing sand is $10.95 \mathrm{~Hz}$ and far away from the fundamental frequency of the model box. Consequently, the model box does not even affect the vibration characteristics of the tailing sand in the test and the natural frequency of the model box meets the requirements of the shaking table test. And this can be described in papers by Li et al. [27] (2017), Cai et al. (2014) [43], Han et al. (2013) [44], and Chen et al. (2010) [28]. The damping ratio of the model tailing sand is $6.85 \%$ (take the average of the six measurements, as shown in Table 3.) and approximately 3.2 times that of the model box; further, the damping of the tailing sand is the main factor in vibration. The damping of the model box will not affect the vibration of the model foundation, obviously. Hence, this is considered reasonable according to the viewpoints of $\mathrm{Wu}$ et al. (2002) [45], Yang et al. (2004) [46], and Chen et al. (2010) [28]. 


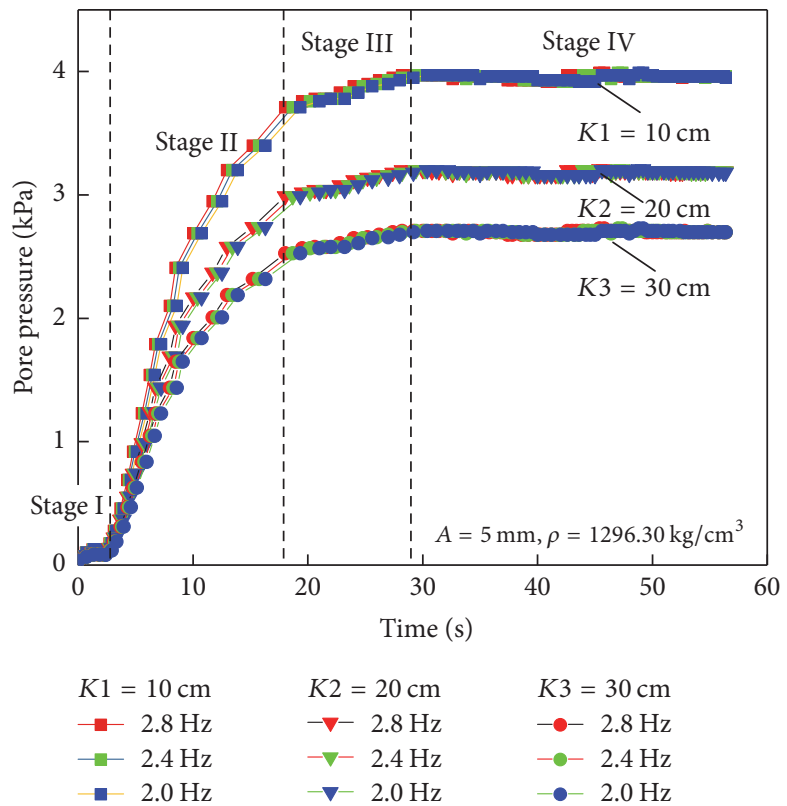

(a)

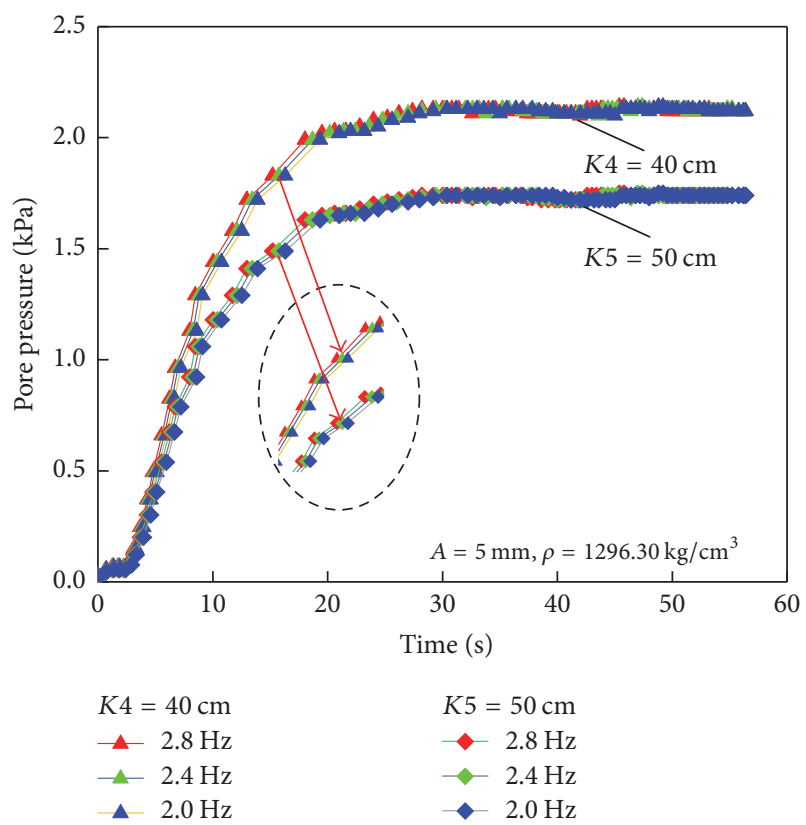

(b)

FIGURE 4: Variation of the pore pressure with time with respect to the vibration frequency.

TABLE 3: The natural frequencies and damping ratios of the tailing sands.

\begin{tabular}{lcccccc}
\hline Test number & I & II & III & IV & V & VI \\
\hline $\begin{array}{l}\text { Fundamental frequency } \\
\text { (Hz) }\end{array}$ & 11.59 & 10.65 & 11.92 & 10.95 & 10.66 & 10.78 \\
Damping ratio (\%) & 7.21 & 6.89 & 7.15 & 6.58 & 6.74 & 6.55 \\
\hline
\end{tabular}

\section{Effects of Various Factors on Tailing Pore Pressure under Dynamic Loading}

3.1. Vibration Frequency. Shaking table tests were conducted using different vibration frequencies, namely, 2.0, 2.4, and $2.8 \mathrm{~Hz}$, respectively, while maintaining a constant vibration amplitude and tailing density $(A=5 \mathrm{~mm}, \rho=$ $\left.1296.30 \mathrm{~kg} / \mathrm{cm}^{3}\right)$. The tests were used to determine the relationship between the tailing pore pressure $u$ and the vibration time $t$ with respect to the vibration frequency, as shown in Figure 4 . As indicated by the features of the curves in the figure, the tailing pore pressure varies exclusively in four stages for each of the considered frequencies: slow increase (stage I), rapid increase (stage II), inducement of structural failure (stage III), and inducement of complete liquefaction (stage IV).

Using the case of a vibration frequency of $2.8 \mathrm{~Hz}$ as an example, the features of the four variation stages of the pore water pressure are as follows:

(1) Slow increase (stage I): over the first $2 \mathrm{~s}$ of the vibration, the gravity of the tailing dam induces compaction and establishes overall stability. The pore water pressure increase is slow and stable.
(2) Rapid increase (stage II): between 2 and $19 \mathrm{~s}$, the pore pressure significantly increases by about $3.6 \mathrm{kPa}$, following a convex growth pattern.

(3) Inducement of structural failure (stage III): between approximately 19 and $28 \mathrm{~s}$, the pore pressure increases linearly and slowly, implying a slower increase of the pore water pressure. The tailing dam begins to liquefy but not significantly.

(4) Inducement of complete liquefaction (stage IV): beyond $28 \mathrm{~s}$, the rate of the pore pressure increase noticeably decreases, with the value eventually plateauing. At this point, the pore water pressure is at its critical value. The internal architecture of the tailing dam is completely destroyed and the dam body is entirely liquefied. As the test proceeds further, the pore water pressure slightly fluctuates about the critical value.

The time of the complete tailing dam failure is the liquefaction time, and the corresponding pore pressure is the critical pore pressure (Feng and Zhang [40]). The relationships between the depth and the dam liquefaction time and critical pore pressure are, respectively, shown in Figure 5. It can be seen that, for a given dam depth, the time required for complete tailing liquefaction decreases with increasing frequency, agreeing with the findings of Zhang and Wang [38]. Further, for a given vibration frequency, the critical pore pressure decreases with increasing height from the bottom of the dam, whereas the liquefaction time initially decreases and then increases. At a height of $10 \mathrm{~cm}$ (depth of $50 \mathrm{~cm}$ from the top of the dam), the vibration time for complete liquefaction at $2.0 \mathrm{~Hz}$ is $7.2 \%$ longer than that at $2.8 \mathrm{~Hz}$, but only $6.1 \%$ longer than that at a height of $30 \mathrm{~cm}$. This 


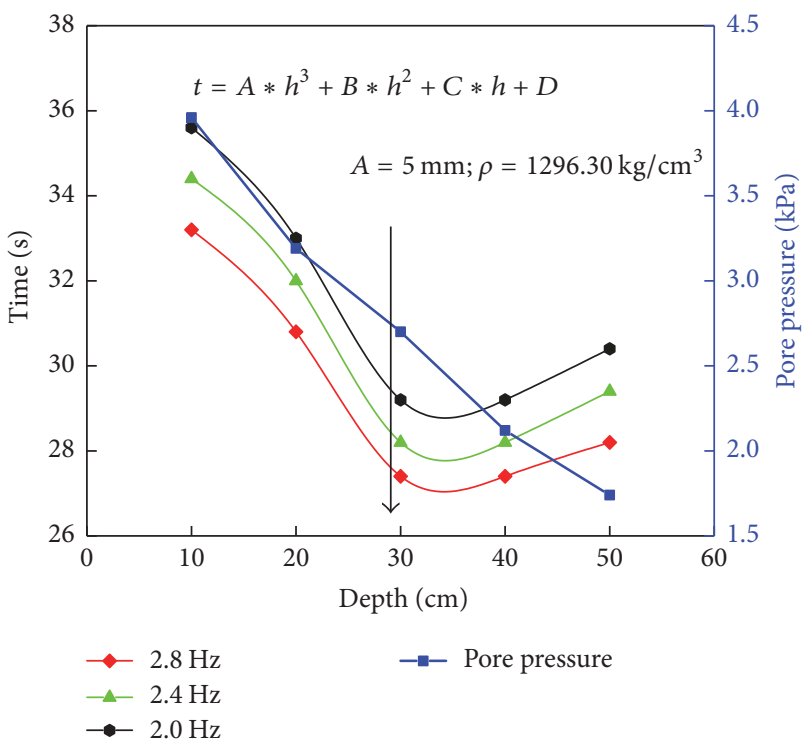

Figure 5: Relationship between the liquefaction time and the height from the base of the dam with respect to the vibration frequency.

implies that the liquefaction time varies nonlinearly with the vertical position of the dam, and a nonlinear method should therefore be adopted in an analysis of the factors that determine the pore water pressure (Xin [47]). The test observations also indicate that, for a given pore pressure, the vibration time significantly decreases with increasing vibration frequency, indicating a significant effect of the vibration on the pore pressure. The relationship between the depth and the time required for complete liquefaction of the tailing dam with respect to the vibration frequency is approximated by

$$
\begin{aligned}
\left.t\right|_{f=2.0 \mathrm{~Hz}} & =0.001 h^{3}-0.04929 h^{2}-0.7929 h+190.4 \\
R^{2} & =0.9733 \\
\left.t\right|_{f=2.4 \mathrm{~Hz}} & =0.001083 h^{3}-0.05821 h^{2}-0.4905 h+182.2 \\
R^{2} & =0.9703 \\
\left.t\right|_{f=2.8 \mathrm{~Hz}} & =0.00075 h^{3}-0.0325 h^{2}-h+179 \\
R^{2} & =0.9729 .
\end{aligned}
$$

3.2. Vibration Amplitude. The different parts of a structure experience different seismic intensities during an earthquake, as characterized by the vibration amplitude, which is an essential parameter. To determine the effect of the amplitude on the tailing pore water pressure, the latter was observed under dynamic loading of the dam using different vibration amplitudes while maintaining the output frequency and tailing density constant $\left(f=2.0 \mathrm{~Hz} ; \rho=1296.30 \mathrm{~kg} / \mathrm{cm}^{3}\right)$. As shown in Figure 6, the pore water pressure increases monotonically with time for amplitudes of 3,4 , and $5 \mathrm{~mm}$, with the rate of increase higher at the beginning of the vibration and dissipating toward the end. Using location $k 1$

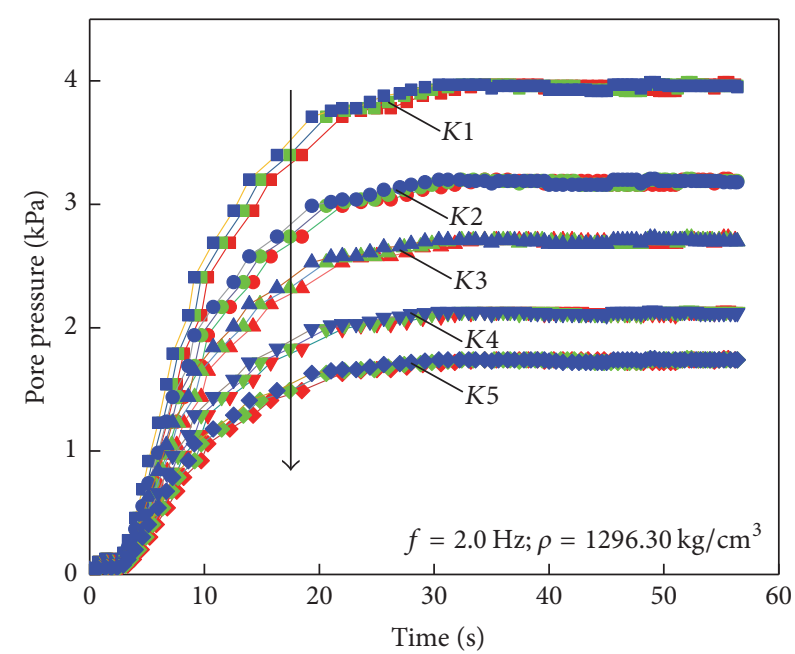

$$
\begin{array}{ll}
K 1=10 \mathrm{~cm} & K 3=30 \mathrm{~cm} \\
-\quad-3 \mathrm{~mm} & -3 \mathrm{~mm} \\
K 2=20 \mathrm{~cm} & K 4=40 \mathrm{~cm} \\
-3 \mathrm{~mm} & -\quad-\quad-5 \mathrm{~mm} \\
-\quad 4 \mathrm{~mm} & \rightarrow-\nabla \mathrm{mm} \\
-5 \mathrm{~mm} & -5 \mathrm{~mm}
\end{array}
$$

$K 5=50 \mathrm{~cm}$

$-3 \mathrm{~mm}$

$-4 \mathrm{~mm}$

$-5 \mathrm{~mm}$

FiguRE 6: Variation of the pore pressure with time with respect to the vibration amplitude.

as an example, for a given depth, the times required for the tailing pore water pressure to reach the critical value are $40.4,38.0$, and $35.6 \mathrm{~s}$ for vibration amplitudes of 3,4 , and $5 \mathrm{~mm}$ of the dynamic loading. This indicates that, with increasing amplitude, the antiliquefaction capacity of the tailing dam is enhanced and the pore pressure growth curve becomes less steep. These observations are consistent with the pore pressure variation pattern described in Section 3.1, namely, an initial slow increase (stage I), followed by a rapid increase (stage II), and then the inducements of structural failure (stage III) and complete liquefaction of the dam (stage IV).

As can be seen from Figure 7, for a given vibration frequency, the trends of the pore pressure versus time curves for the different depths are synchronized. However, for a given depth, the time to complete liquefaction shortens with increasing vibration amplitude. Uniformly sized pores are formed in the tailing after extended vibration with a small amplitude and within a shorter time with a larger amplitude. For a given vibration amplitude, the critical pore pressure decreases with increasing height from the bottom of the dam, while the liquefaction time initially decreases and then increases. At a height of $10 \mathrm{~cm}$, the dam liquefaction time decreases by $5.9 \%$ from $40.4 \mathrm{~s}$ to $38.0 \mathrm{~s}$ when the vibration amplitude increases from $3 \mathrm{~mm}$ to $4 \mathrm{~mm}$ and by a further $12.8 \%$ to $35.6 \mathrm{~s}$ when the amplitude increases from $4 \mathrm{~s}$ to $5 \mathrm{~mm}$. This implies a reduction in the antiliquefaction capacity of the tailing dam with increasing vibration amplitude and that the vibration amplitude significantly affects the dam. The liquefaction time of the tailing dam varies nonlinearly with 


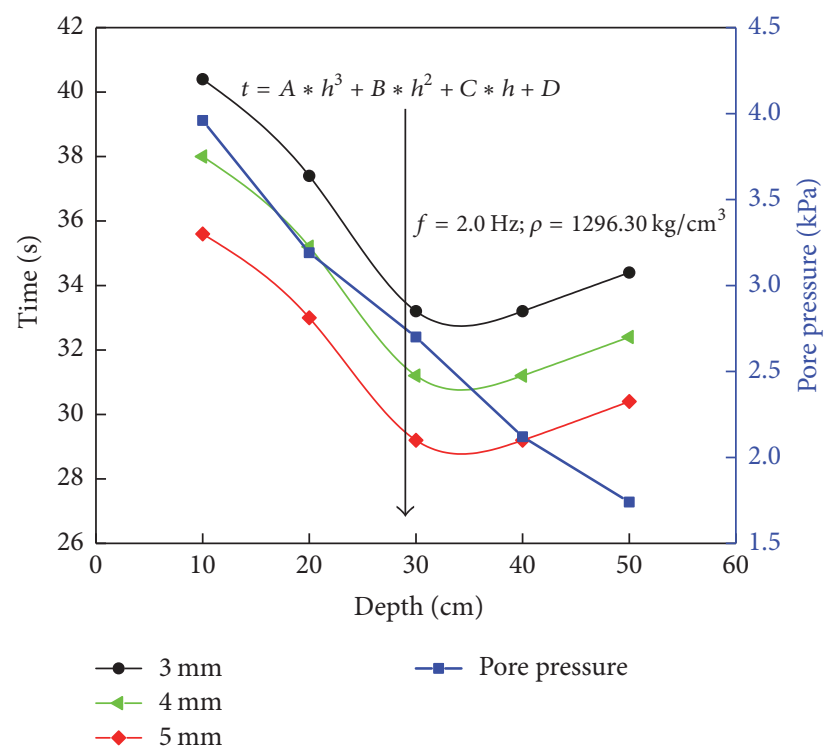

FIGURE 7: Relationship between the liquefaction time and the height in the dam with respect to the vibration amplitude.

the height from the base, as approximated by (2) with respect to the vibration amplitude.

$$
\begin{aligned}
\left.t\right|_{A=3 \mathrm{~mm}} & =0.001 h^{3}-0.045 h^{2}-1.15 h+217.6 \\
R^{2} & =0.9743 \\
\left.t\right|_{A=4 \mathrm{~mm}}= & 0.001 h^{3}-0.04714 h^{2}-0.9714 h+204 \\
R^{2}= & 0.9738 \\
\left.t\right|_{A=5 \mathrm{~mm}}= & 0.001 h^{3}-0.04929 h^{2}-0.7929 h+190.4 \\
R^{2}= & 0.9733 .
\end{aligned}
$$

3.3. Tailing Sand Density. The density of a tailing sand varies with the geological conditions, tailing particle composition, and compactness. Figure 8 shows the relationship between the tailing pore water pressure and time for given vibration frequency and amplitude $(f=2.0 \mathrm{~Hz} ; A=5 \mathrm{~mm})$ and different tailing densities. As can be seen from the experimental results, at a given height in the dam, the pore water pressure increases significantly more rapidly in a loose tailing, with the critical value attained within a short period. This implies that the tailing dam is more easily liquefied and substantiates the usefulness of vibrocompaction and sand compaction piling in engineering construction (Xie [1], Liu [48]).

As can also be observed from Figure 9, at a height of $10 \mathrm{~cm}$, the antiliquefaction capacity of the tailing increases rapidly with increase of the tailing density from $1111.11 \mathrm{~kg} / \mathrm{cm}^{3}$ to $1296.30 \mathrm{~kg} / \mathrm{cm}^{3}$. Figure 8 further shows that there is a decrease in the rate of increase of the pore pressure as the liquefaction time changes from $28.6 \mathrm{~s}$ to $35.6 \mathrm{~s}$, representing a further increase of $24.5 \%$. When the tailing density is increased to $1666.67 \mathrm{~kg} / \mathrm{cm}^{3}$, the liquefaction time further increases to $43.8 \mathrm{~s}$, representing a $53.1 \%$ increase relative to the value for a density of $1111.11 \mathrm{~kg} / \mathrm{cm}^{3}$. This shows that the tailing density significantly impacts the liquefaction. The liquefaction time varies nonlinearly with the height in the dam, as approximated by (3) for different densities. In addition, the pore pressure growth curves for all three considered tailing densities are S-shaped, substantiating the four stages mentioned in Section 3.1, namely, slow increase (stage I), rapid increase (stage II), inducement of structural failure (stage III), and inducement of complete liquefaction (stage IV).

$$
\begin{aligned}
\left.t\right|_{\rho=1296.30 \mathrm{~kg} / \mathrm{cm}^{3}=} & 0.00067 h^{3}-0.02786 h^{2}-0.9452 h \\
& +155 \\
R^{2}= & 0.9749 \\
\left.t\right|_{\rho=1111.11 \mathrm{~kg} / \mathrm{cm}^{3}=} & 0.001 h^{3}-0.04930 h^{2}-0.7930 h \\
& +191.4 \\
R^{2}= & 0.9733 \\
\left.t\right|_{\rho=1666.67 \mathrm{~kg} / \mathrm{cm}^{3}=} & 0.001 h^{3}-0.04285 h^{2}-1.39 h \\
& +231.1 \\
R^{2}= & 0.9747 .
\end{aligned}
$$

\section{Model of Tailing Pore Pressure Growth under Dynamic Loading}

4.1. S-Shaped Growth Model. The classical model of the vibration-affected pore water pressure proposed by Seed et al. [9] is more applicable to a sandy soil, while the model of the pore water pressure in tailing silt proposed by $\mathrm{Du}$ et al. [19] works well for cyclic loading. Hence, to better predict the tailing pore pressure under dynamic loading, the BiDoseResp function [19] was used to perform respective nonlinear fitting based on the determined relationship between the pore water pressure and time with respect to various influencing factors and the pore water pressure characteristics at different stages. This was used to obtain the following S-shaped pore water pressure model of tailing sand under dynamic loading:

$$
\begin{aligned}
u= & A_{1}+\left(A_{2}-A_{1}\right) \\
& \times\left(\frac{P}{1+10^{\left(B_{1}-t\right) h_{1}}}+\frac{1-P}{1+10^{\left(B_{2}-t\right) h_{2}}}\right),
\end{aligned}
$$

where $u$ is the pore water pressure, $t$ is the vibration time, $A_{1}$ and $A_{2}$ (Figure 10) are, respectively, the ranges of the model, $h_{1}$ and $h_{2}$ are, respectively, the curve gradients during the stage of the rapid increase of the pore pressure variation and the stage of inducement of structural failure, and $B_{1}$ and $B_{2}$ are fitting parameters.

Figure 11 shows the experimental results and corresponding fitting curves for the seven considered scenarios, while Table 4 presents the fitting parameters of the model. As can 


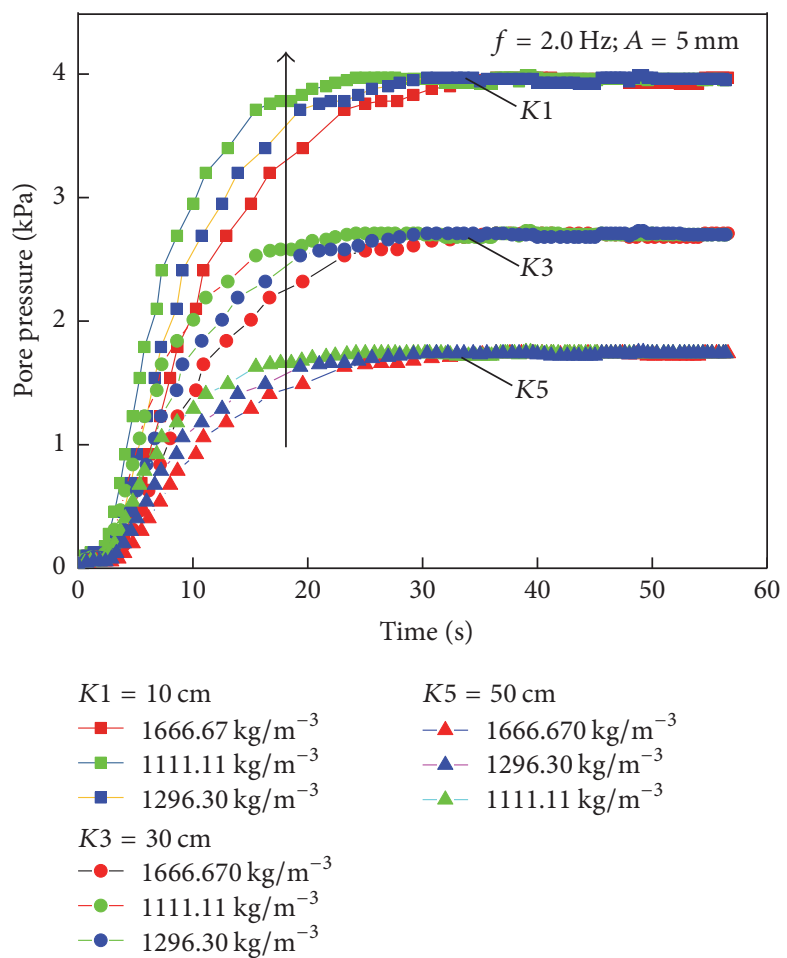

(a)

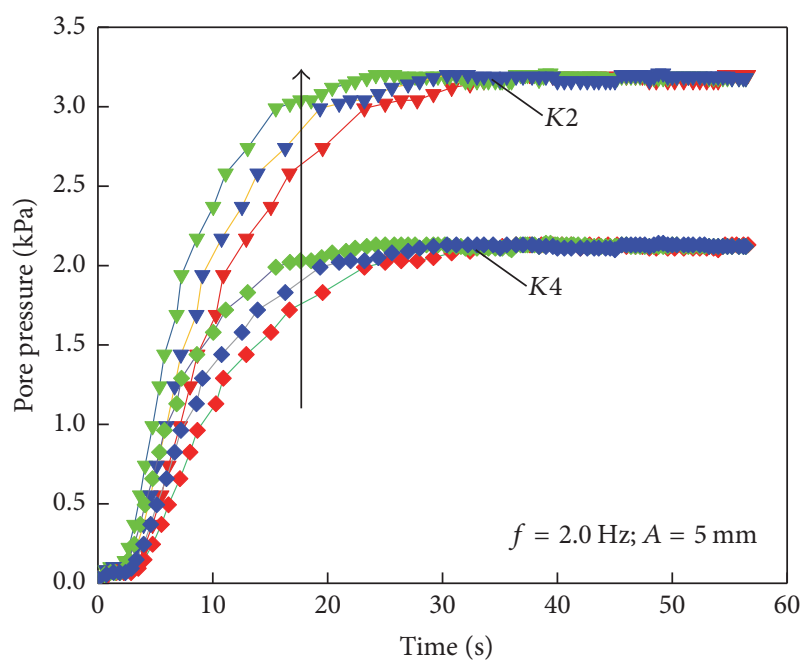

$$
\begin{array}{ll}
K 2=20 \mathrm{~cm} & K 4=40 \mathrm{~cm} \\
\neg-1666.67 \mathrm{~kg} / \mathrm{m}^{-3} & \bullet-1666.67 \mathrm{~kg} / \mathrm{m}^{-3} \\
\nabla-1296.30 \mathrm{~kg} / \mathrm{m}^{-3} & \bullet 1296.30 \mathrm{~kg} / \mathrm{m}^{-3} \\
\rightarrow-1111.11 \mathrm{~kg} / \mathrm{m}^{-3} & -\sim 1111.11 \mathrm{~kg} / \mathrm{m}^{-3}
\end{array}
$$

FIGURE 8: Variation of the pore pressure with time with respect to the tailing density.

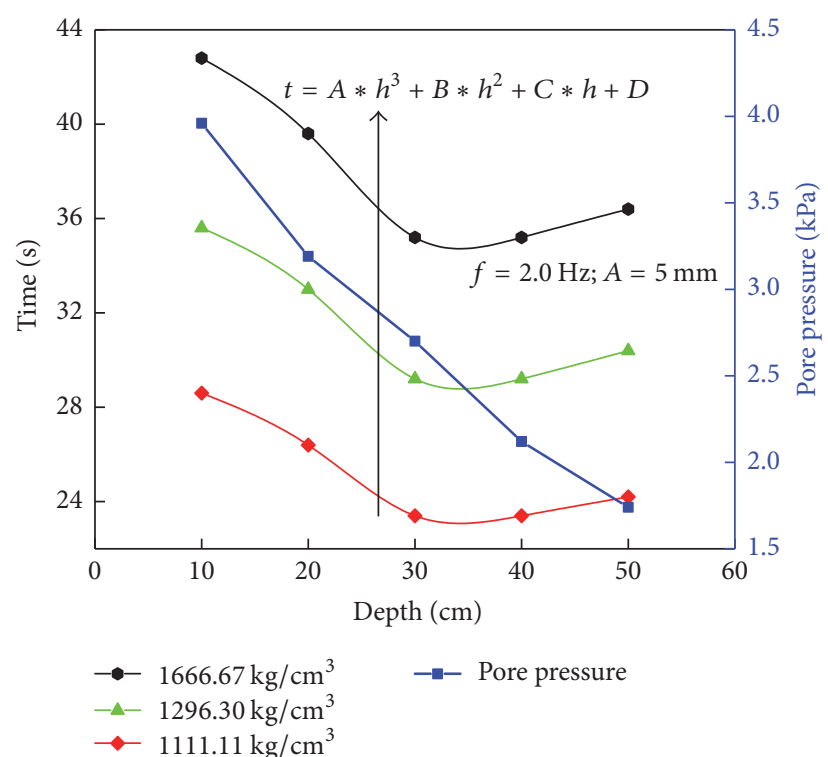

FIGURE 9: Relationship between the liquefaction time and the height in the dam with respect to the tailing density.

be observed from the figure and table, the S-shaped model best describes the experimental results, having correlation coefficients of at least 0.999 for each of the seven scenarios. A general rule can also be deduced from Figure 10, namely, that the pore water pressure in the tailing slowly increases during the first $5 \mathrm{~s}$ of the vibration, with the subsequent increase

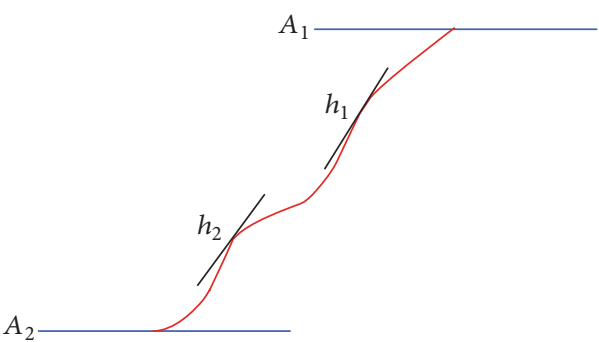

Figure 10: The image feature of BiDoseResp function.

being more obvious (i.e., an S-shaped growth). The increase of the tailing pore water pressure mostly occurs during the first $30 \mathrm{~s}$ of the vibration, with the pressure being almost constant afterward, indicating complete liquefaction of the tailing dam.

With respect to the experimental results presented in Figures 4, 6, and 8, the S model indicates that the external forces are all borne by the tailing prior to vibration and that the water is subjected to only its own pressure. The tailing structure is thus stable. When vibration commences, the skeleton of the tailing is subjected to inertial and interference forces. Because the quality and arrangement of the tailing particles differ, their initial stress and the intensity of the dynamic load transferred to each point also differ. There are thus significant differences among the magnitude, direction, and actual effects of the forces borne by each sand particle, and this results in differing stresses at the points of contact 
TABLE 4: Parameters of the fitting model.

\begin{tabular}{lcccccccc}
\hline Test number & $A_{1}$ & $A_{2}$ & $B_{1}$ & $B_{2}$ & $h_{1}$ & $h_{2}$ & $P$ \\
\hline$(1)$ & -0.0971 & 3.95669 & 29.88359 & 59.1634 & 0.06979 & 0.0223 & 0.45909 & 0.99944 \\
$(2)$ & -0.0936 & 3.94753 & 34.83684 & 54.4203 & 0.02433 & 0.028653 & 0.96198 & 0.99901 \\
$(3)$ & -0.0891 & 3.94847 & 33.62098 & 38.8706 & 0.02518 & 0.029539 & 0.9715 & 0.99913 \\
$(4)$ & -0.0913 & 3.95517 & 33.88593 & 67.492 & 0.06132 & 0.01983 & 0.4645 & 0.99940 \\
$(5)$ & -0.0939 & 3.95616 & 31.92177 & 63.40831 & 0.06486 & 0.02098 & 0.46402 & 0.99942 \\
$(6)$ & -0.09619 & 3.95721 & 23.92759 & 47.45361 & 0.08682 & 0.0279 & 0.46101 & 0.99948 \\
$(7)$ & -0.08678 & 3.95144 & 35.73362 & 71.36408 & 0.05828 & 0.01898 & 0.46317 & 0.99942 \\
\hline
\end{tabular}
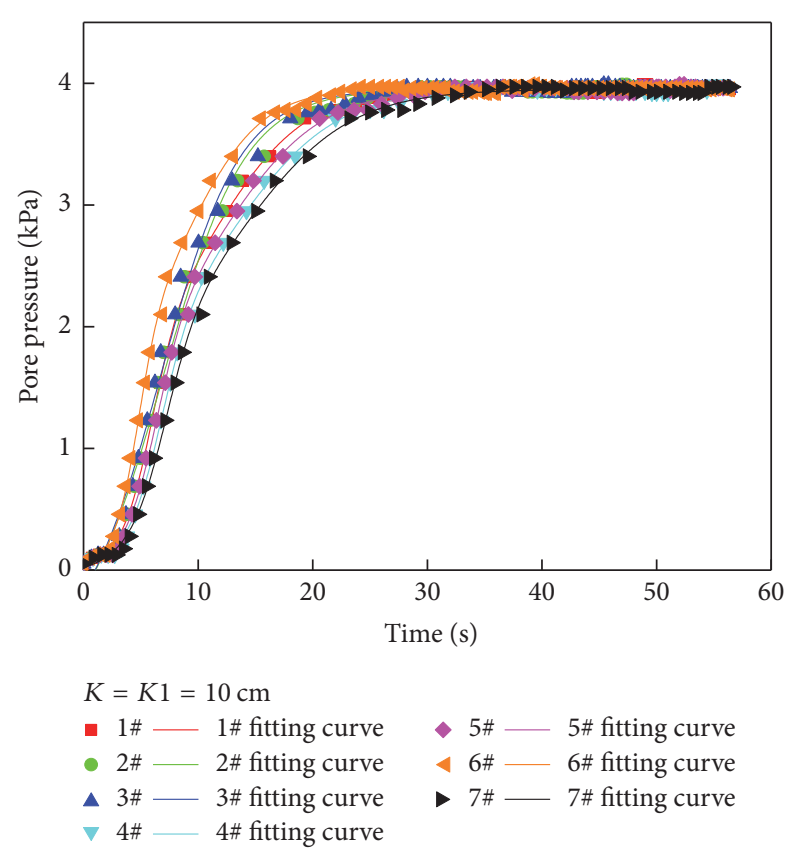

FIGURE 11: Test results for seven different scenarios and the fitted Sshaped curves of the pressure model.

among the particles. At this time, the increase in the pore water pressure is slow (i.e., stage I). When the stress exceeds a certain value, it would destroy the original connective strength and structure between tailing particles. This leads to separation of the particles, which then bear the load individually, resulting in a rapid increase in the pore water pressure (stage II). When the pore water pressure further increases to a certain value, the water would be pushed upward by the excess hydrostatic pressure, while the tailing particles would move downward under their own weight. This induces structural failure (stage III). Before complete structural damage, the sinking tailing particles are blocked by the rising extruded pore water, leaving the former in a partial or total suspended state. The shear strength is eventually entirely lost and the tailing is completely liquefied (stage IV). The pore water, however, continues to discharge for some time, and this helps to stabilize the pore water pressure.

Figure 12 shows the relationship between the measured pore pressure and that predicted by the S-shaped model. The measured and predicted values for the seven scenarios can be observed to cluster around the line of equality [49],

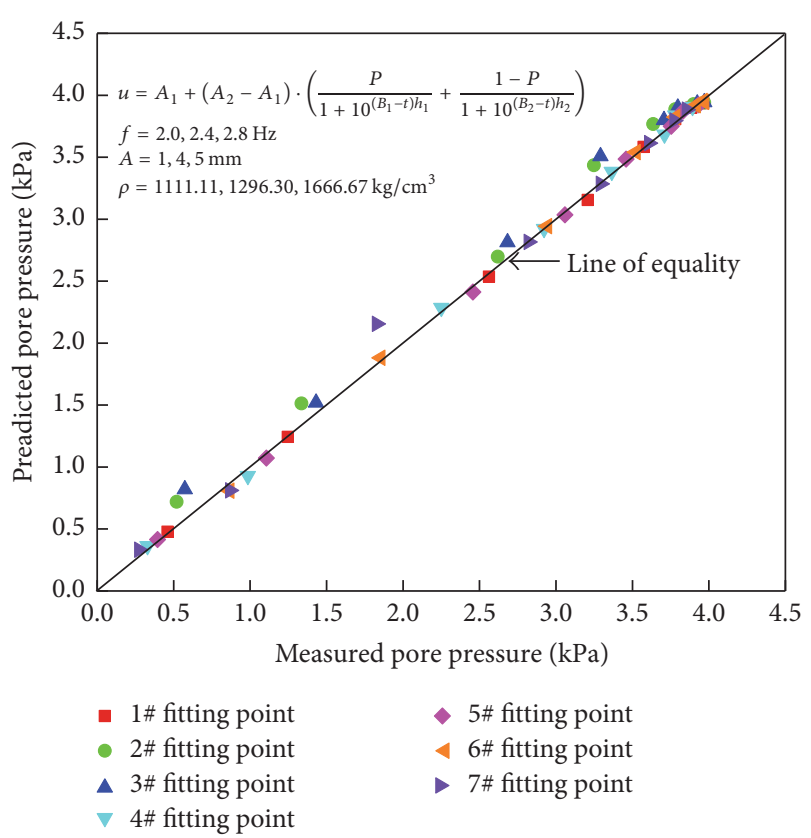

FIGURE 12: Relationship between the measured and predicted pore pressures.

demonstrating the effectiveness of the model for predicting the tailing pore water pressure under dynamic loading.

4.2. Regression Analysis of Pore Pressure Prediction by Model. The correlation between the three influencing factors and the critical pore pressure was calculated by the SPSS program using multivariate nonlinear regression. Table 5 presents the results for location $K 1$, with a greater correlation coefficient and a significance closer to 0 implying greater effect on the critical pore water pressure. As shown in the table, the frequency and amplitude are positively correlated with the pore water pressure, while the density is negatively correlated with it. This indicates that the effects of the frequency and amplitude on the pore pressure are opposite to that of the density. The correlation coefficients between the frequency and the critical pore pressure (0.999) and the corresponding significance (0.033) are greater than those for the amplitude ( 0.979 correlation coefficient and 0.130 significance). The correlation coefficient of the density with the critical pore pressure is -0.982 , indicating that the pore pressure decreases with increasing density, which is consistent with the results 
TABLE 5: Parameters of the single correlations between the critical pore pressure and its three influencing factors.

\begin{tabular}{lccc}
\hline Influencing factor & Frequency $f$ & Amplitude $A$ & Density $\rho$ \\
\hline $\begin{array}{l}\text { Correlation } \\
\text { coefficient }\end{array}$ & 0.999 & 0.979 & -0.982 \\
Significance & 0.033 & 0.130 & 0.121 \\
\hline
\end{tabular}

TABLE 6: Parameters of the single correlations between the predicted critical pore pressure and its three influencing factors.

\begin{tabular}{lccc}
\hline Influencing factor & Frequency $f$ & Amplitude $A$ & Density $\rho$ \\
\hline $\begin{array}{l}\text { Correlation } \\
\text { coefficient }\end{array}$ & 0.985 & 0.961 & -0.981 \\
Significance & 0.110 & 0.179 & 0.123 \\
\hline
\end{tabular}

in Figure 8. A comparison of the significance values shows that the order of the degrees of the respective effects of the three factors on the liquefaction of the tailing sand at a given location on the dam is as follows: frequency $>$ density $>$ amplitude, which agrees with the indications of Figures 5, 7, and 9 .

Table 6 gives the parameters of the single correlations between the critical pore pressure at point $k 1$ and the three influencing factors, as determined from the S-shaped model. By comparing Tables 4 and 5 , it can be seen that the $S$ model is more effective for predicting the tailing pore water pressure under dynamic loading. The order of the degrees of the respective effects of the three factors on the tailing liquefaction is as follows: frequency $>$ amplitude $>$ density.

Considering that the correlation coefficients of the three influencing factors with the critical pore pressure differ, the joint relationship of the former with the latter would be nonlinear. Equation (5) expresses the results of a multivariate nonlinear regression that was used to examine the joint relationship between the critical pore pressure and its three influencing factors, namely, the vibration frequency, vibration amplitude, and density:

$$
\begin{aligned}
u_{d \max }= & -5.768-0.0015 f+0.0736 A+6.1465 \lg \rho \\
& -0.0087 A^{2}-0.9858 \lg \rho^{2},
\end{aligned}
$$

where $u_{d \max }$ is the critical pore pressure, $f$ is the vibration frequency, $A$ is the vibration amplitude, and $\rho$ is the tailing density. The equation represents the relationship between the tailing liquefaction and the vibration frequency, vibration amplitude, and tailing density at a given depth and time. The nonlinear function was derived based on the measured data for the seven scenarios and the degrees of the respective single correlations between the critical pore pressure and its influencing factors, as represented in Tables 4 and 5. The function can be used as a reference for a more accurate assessment of the stability of a tailing dam under dynamic loading.

\section{Conclusions}

In this study, shaking table tests were used to investigate the effects of dynamic loading on a tailing dam, with particular emphasis on the effects of the vibration frequency, vibration amplitude, and the tailing density on the pore water pressure, with respect to the vibration duration and the location on the dam. Following is a summary of the study findings.

(1) There are four stages in the increase of the tailing pore pressure under dynamic loading: slow increase (stage I), rapid increase (stage II), inducement of structural failure (stage III), and inducement of complete liquefaction (stage IV).

(2) Extended vibration is required to form uniformly sized pores in dense tailing, especially when the vibration frequency is low and the amplitude is small, whereas a shorter time is required for the same in less dense tailing, especially under high-frequency largeamplitude vibrations. The liquefaction time initially decreases and then increases with increasing height from the base of a tailing dam under the influence of each of the above three influencing factors, whereas the critical pore pressure continuously decreases.

(3) The growth of the tailing pore water pressure can be described by a multiparameter S-shaped model. Comparison of the pore pressures predicted by the developed model with the measured values verified the effectiveness of the model.

(4) By multivariate nonlinear regression, the order of the degrees of the respective effects of the three influencing factors of the critical pore pressure of the tailing was found to be frequency $>$ density $>$ amplitude. A nonlinear function of the critical pore pressure in terms of the above three factors was derived taking into consideration the respective degrees of the correlations of the factors with the pore pressure. The function can be used as a reference for a more accurate prediction of the stability of a tailing dam under dynamic loading.

\section{Conflicts of Interest}

The authors declare that there are no conflicts of interest regarding the publication of this article.

\section{Acknowledgments}

The project is supported by the National Natural Science Foundation of China (Grant no. 51504123), the general grant of Liaoning Provincial Education Department (Grant No. L2015211), and the Natural Science Foundation of Liaoning Province (Grant no. 20170540417).

\section{References}

[1] D. Y. Xie, Soil Dynamics, Xi’an Jiaotong University Press, Xiłan, China, 1988. 
[2] T.-S. Ueng, Z.-F. Wang, M.-C. Chu, and L. Ge, "Laboratory tests for permeability of sand during liquefaction," Soil Dynamics and Earthquake Engineering, vol. 100, pp. 249-256, 2017.

[3] L. C. Yu, N. Takuya, M. Tomohiro, and M. Nakashima, "Seismic resistance capacity of beam-column connections in high-rise buildings: E-Defense shaking table test," Earthquake Engineering \& Structural Dynamics, vol. 40, no. 6, pp. 605-622, 2011.

[4] Y. Wang and Y.-L. Wang, "Liquefaction characteristics of gravelly soil under cyclic loading with constant strain amplitude by experimental and numerical investigations," Soil Dynamics and Earthquake Engineering, vol. 92, pp. 388-396, 2017.

[5] K. N. Le and M. Ghayoomi, "Cyclic direct simple shear test to measure strain-dependent dynamic properties of unsaturated sand," Geotechnical Testing Journal, vol. 40, no. 3, pp. 381-395, 2017.

[6] G. Biondi, M. R. Massimino, and M. Maugeri, "Experimental study in the shaking table of the input motion characteristics in the dynamic SSI of a SDOF model," Bulletin of Earthquake Engineering, vol. 13, no. 6, pp. 1835-1869, 2015.

[7] D. Forcellini and A. M. Tarantino, "Assessment of stone columns as a mitigation technique of liquefaction-induced effects during Italian earthquakes (May 2012)," The Scientific World Journal, vol. 2014, Article ID 216278, 8 pages, 2014.

[8] N. Ural and Z. Gunduz, "Behavior of nonplastic silty soils under cyclic loading," The Scientific World Journal, vol. 2014, Article ID 635763, 12 pages, 2014.

[9] H. B. Seed, P. P. Martin, and J. Lysmer, "Pore-water pressure changes during soil liquefaction," Journal of Geotechnical and Geoenvironmental Engineering, vol. 102, no. 4, pp. 323-346, 1976.

[10] G. R. Martin, W. D. Finn, and H. B. Seed, "Fundamentals of liquefaction under cyclic loading," Journal of the Geotechnical Engineering Division, vol. 101, no. 5, pp. 423-438, 1975.

[11] T. T. Nhan, H. Matsuda, and H. Sato, "A model for multidirectional cyclic shear-induced pore water pressure and settlement on clays," Bulletin of Earthquake Engineering, vol. 15, no. 7, pp. 2761-2784, 2017.

[12] G. X. Chen and X. Z. Liu, "Study on dynamic pore water pressure in silty clay interb edded with fine sand of Nanjing," Chinese Journal of Geotechnical Engineering, vol. 26, no. 1, pp. 79-82, 2004.

[13] H.-Y. Zhuang, X.-Z. Liu, and G.-X. Chen, "Study on dynamic parameters and seismic response of interbedded soil," Rock and Soil Mechanics, vol. 26, no. 9, pp. 1495-1498, 2005.

[14] B. Huang, X. B. Rao, Z. Q. Chen et al., "Study on pore water pressure developing model of saturated sand under cyclic loading," World Earthquake Engineering, vol. 26, no. 1, pp. 4650, 2010.

[15] Y. Y. Cai, S. E. Hu, H. C. Jiang et al., "Experimental study on the law of development of pore water pressure for coastal aeolian sand subjected to cyclic loading," Chinese Journal of Underground Space and Engineering, vol. 12, no. 5, pp. 1211-1218, 2016.

[16] C. L. Chen, J. F. He, Z. Q. Hu et al., "Developing characteristics of pore water pressure and residual deformation of tailings sands under cyclic load," Chinese Journal of Rock Mechanics and Engineering, vol. 25, no. 2, 2006 (Chinese).

[17] C. Zhang, C. H. Yang, and S. W. Bai, "Experimental study on dynamic characteristics of tailings material," Rock and Mechanics, vol. 27, no. 1, pp. 35-40, 2006.

[18] F. Tan, X. B. Rao, B. Huang et al., "Experimental study of the Dynamic characteristics of tailings silts," China Earthquake Engineering Journal, vol. 37, no. 3, pp. 772-777, 2015.
[19] Y. Q. Du, H. C. Yang, and S. W. Wu, "Pore-water pressure characteristics of tailings silit under cyclic loading," Journal of Northeastern University (Natural Science), vol. 37, no. 4, pp. 583$588,2016$.

[20] S. Z. Liu, H. Z. Li, Y. Shan et al., "Energy method for analyzing dynamic pore water pressure model for tailing soil," Chinese Journal of Geotechnical Engineering, vol. 38, no. 11, pp. 20512058, 2016.

[21] A. W. Crewe, M. L. Ling, C. A. Taylor et al., "Development of a large flexible shear stack for testing dry sand and simple direct foundations on a shaking table," in Proceedings of the 5th SECED Conference on European Seismic Design Practice, 1995.

[22] D. Matthew and M. W. David, "Shaking table evaluation of dynamic soil properties," in Proceedings of the 4th International Conference on Earthquake Geotechnical Engineering, 2007.

[23] H. Mizuno and M. Iiba, "Shaking table testing of seismic building-pile-soil interaction," in Proceeding of the 8th World Conference Earthquake Engineering, 1982.

[24] Y. Z. Zhuang, Y. Chen, B. Chen et al., "Shaking table test on boundary effect of steel box for pile-soil interaction research," Journal of Fuzhou University (Natural Science Edition), vol. 44, no. 4, pp. 504-509, 2016.

[25] P. J. Meymand, Shaking Table Scale Model Tests of Nonlinear Soil-Pile-Superstructure Interaction in Soft Clay, University of California, Berkeley, Calif, USA, 1998.

[26] Y. Q. Chen, X. L. Lv, and W. Huang, "Simulation method of soil boundary conditionin shaking table tests of soil-structure interaction," Structural Engineering, vol. 3, no. 7, pp. 25-30, 2000.

[27] X.-J. Li, X.-H. Wang, L. Li, and J. Han, "Design and performance test of 3D laminar shear container for shaking table," Rock and Soil Mechanics, vol. 38, no. 5, pp. 1524-1532, 2017.

[28] G.-X. Chen, Z.-H. Wang, X. Zuo, X.-L. Du, and X.-J. Han, "Development of laminar shear soil container for shaking table tests," Chinese Journal of Geotechnical Engineering, vol. 32, no. 1, pp. 89-97, 2010.

[29] X.-M. Liu, Q. Sheng, J. Chen, W.-H. Ke, and J.-H. Yang, "Seismic shaking table test for large-scale underground cavern group (II): test scheme," Rock and Soil Mechanics, vol. 36, no. 6, pp. 16831690, 2015.

[30] A. Arias, Measure of Earthquake Intensity, Massachusetts Institute of Technology, Cambridge, Mass, USA; University of Chile, Santiago, Chile, 1970.

[31] X. Liu, H.-M. Tang, C.-R. Xiong, and Q.-B. Liu, "A new method for reliability analysis of dynamic slope stability with considering energy-time distribution," Rock and Soil Mechanics, vol. 36, no. 5, pp. 1428-1454, 2015.

[32] S. Chen, G. X. Chen, C. Z. Qi et al., "A shaking table-based experimental study of seismic response of three-arch type's underground subway station in liquefiable ground," Rock and Soil Mechanics, vol. 36, no. 7, pp. 1899-1914, 2015.

[33] M. Mirshekari and M. Ghayoomi, "Centrifuge tests to assess seismic site response of partially saturated sand layers," Soil Dynamics and Earthquake Engineering, vol. 94, pp. 254-265, 2017.

[34] A. Tombari, M. E. Naggar, and F. Dezi, "Centrifuge tests to assess seismic site response of partially saturated sand layers," Soil Dynamics and Earthquake Engineering, vol. 94, pp. 72-87, 2017.

[35] Y. Guo and L. He, "The influences of the vibration frequencies on liquefaction strength of saturated sands," Journal of Disaster 
Prevention and Mitigation Engineering, vol. 29, no. 6, pp. 618623, 2009.

[36] C. L. Sun, L. T. Shao, and X. X. Guo, "Study on dynamic triaxial test of tailing sand under different vibration frequencies," Mine Research and Development, vol. 35, no. 11, pp. 69-73, 2015.

[37] W. H. Peacock and H. B. Seed, "Sand liquefaction under cyclic loading simple shear conditions," Journal of the Soil Mechanics and Foundations Division, vol. 94, pp. 689-708, 1975.

[38] J. M. Zhang and W. X. Wang, "Influence of vibration frequency on dynamic characteristics of saturated sand," Chinese Journal of Geotechnical Engineering, vol. 12, no. 1, pp. 89-97, 1990.

[39] X. H. Wang and L. Hai, "Study on dynamic steady state strength of sand soil liquefaction," Chinese Journal of Rock Mechanics and Engineering, vol. 22, no. 1, pp. 96-102, 2003.

[40] T. G. Feng and L. M. Zhang, "Experimental study on effect of vibration frequency on dynamic behaviors of saturated loose sands," Journal of Water Resources and Architectural Engineering, vol. 11, no. 3, pp. 11-14, 2013.

[41] R. Zhang, Y. J. Tu, W. P. Fei et al., "Effect of vibration frequency on dynamic properties of saturated cohesive soil," Rock and Soil Mechanics, vol. 37, no. 5, pp. 699-704, 2006.

[42] Y. Yoshimi and H. Oh-Oka, "Influence of degree of shear stress reversal on the liquefaction potential of saturated sand," Soils and Foundations, vol. 15, no. 3, pp. 27-40, 1975.

[43] L. W. Cai, Y. Gu, W. D. Zhuo et al., "The boundary effects of shaking table test soil box based on finite element simulation," in Proceedings of the 23rd National Structural Engineering Conference, 2014.

[44] J. Han, X. Du, and L. Li, "Study on applicability of continuum model box used in shaking table test," Earthquake Engineering and Engineering Vibration, vol. 33, no. 2, pp. 200-208, 2013.

[45] X.-P. Wu, L.-M. Sun, S.-D. Hu, and L.-C. Fan, "Development of laminar shear box used in shaking table test," Journal of Tongji University, vol. 30, no. 7, pp. 781-785, 2002.

[46] L. D. Yang, Q. Q. Ji, Y. L. Zheng et al., "Study on design of test box in shaking table for subway station sturcture in soft soil," Chinese Journal of Geotechnical Engineering, vol. 26, no. 1, pp. 75-78, 2004.

[47] H. B. Xin, "Seismic response analysis of Da-shi-he tailings dam in 1976," Chinese Journal of Geotechnical Engineering, vol. 18, no. 4, pp. 51-59, 1996.

[48] H. L. Liu, "A review of recent advances in soil dynamics and geotechnical earthquake engineering," China Civil Engineering Journal, vol. 45, no. 4, pp. 148-164, 2012.

[49] B. J. Martin and D. Altman, "Statistical methods for assessing agreement between two methods of clinical assessment," The Lancet, vol. 1, no. 8476, pp. 931-936, 1986. 


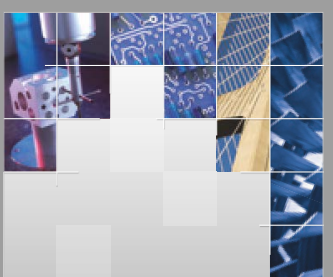

\section{Enfincering}
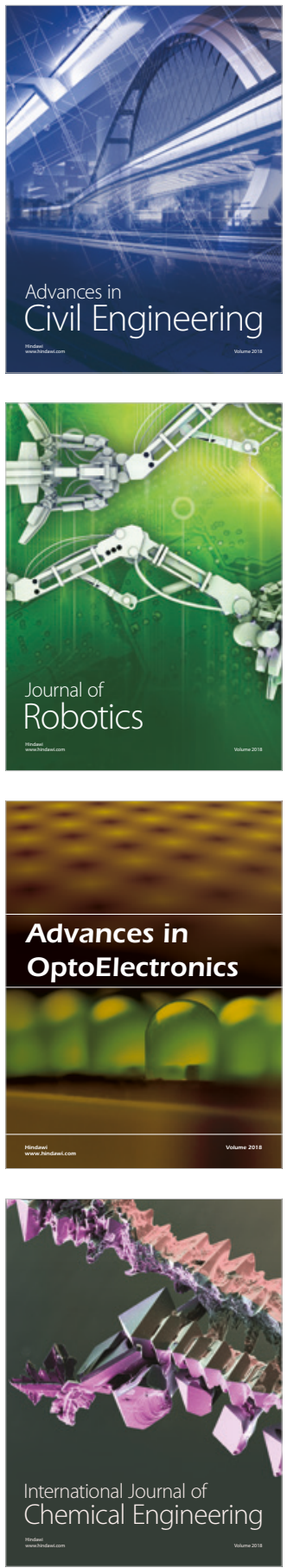

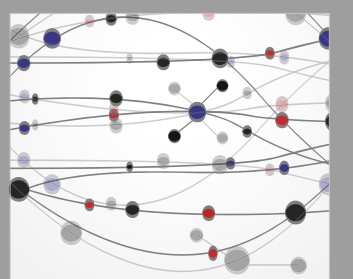

\section{Rotating \\ Machinery}

The Scientific World Journal

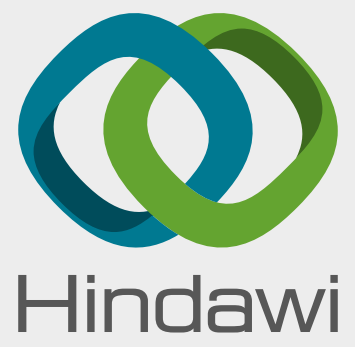

Submit your manuscripts at

www.hindawi.com
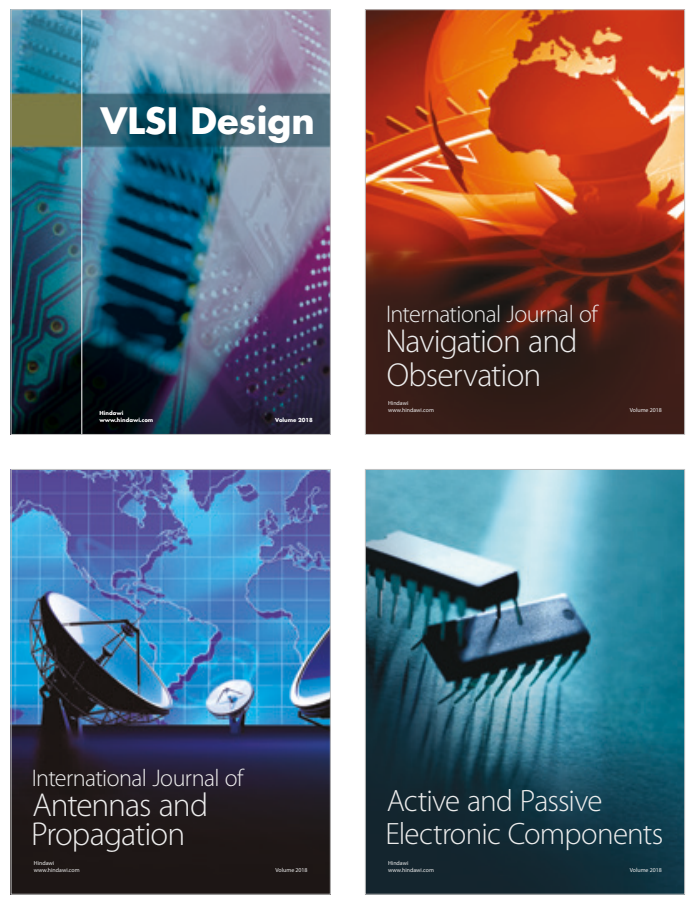
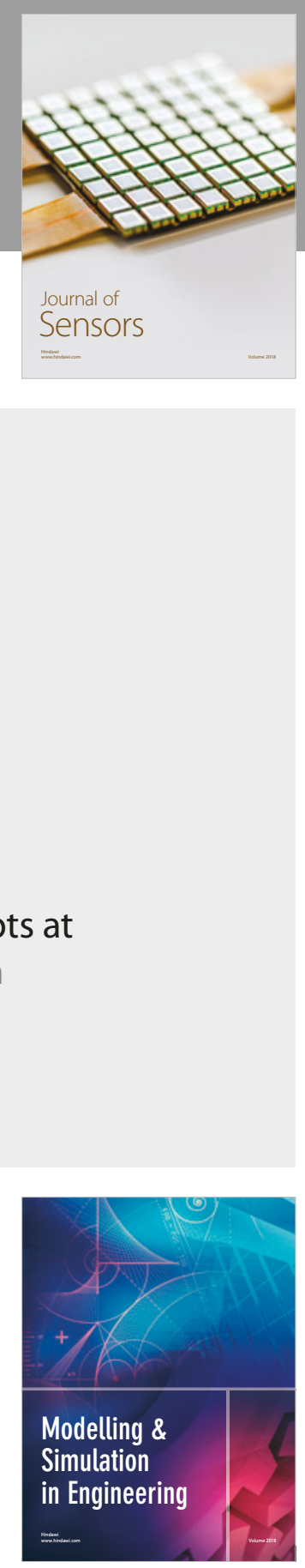

\section{Advances \\ Multimedia}
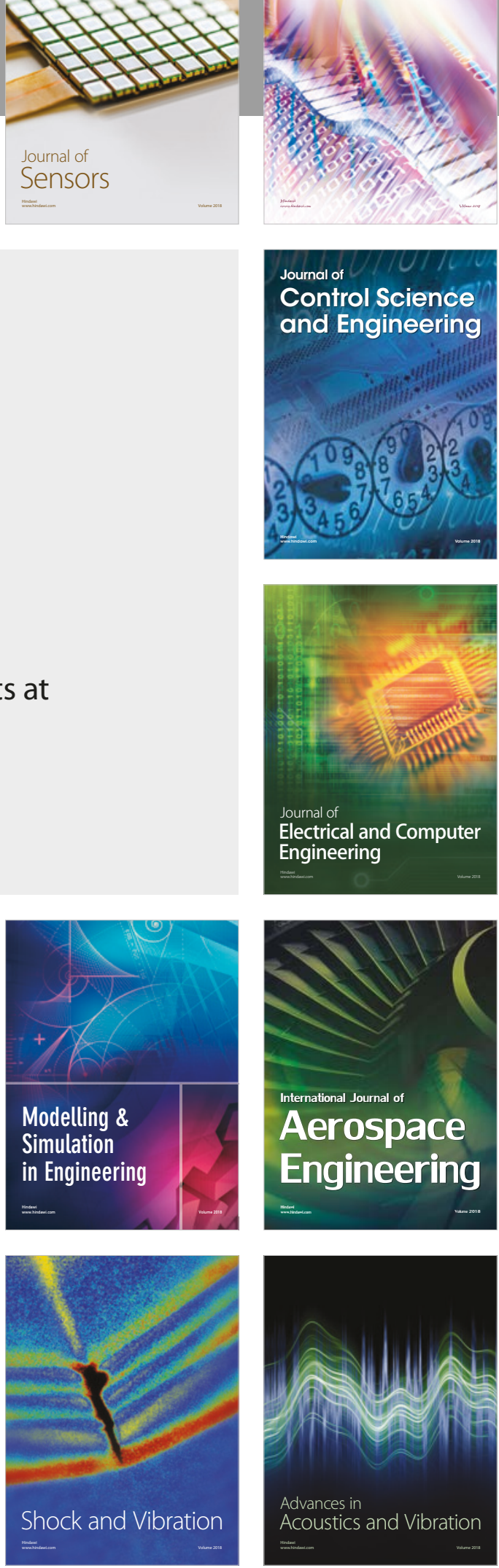